\title{
Interventions to increase smoking cessation at the population level: how much progress has been made in the last two decades?
}

\author{
Shu-Hong Zhu, Madeleine Lee, Yue-Lin Zhuang, Anthony Gamst, \\ Tanya Wolfson
}

Department of Family and Preventive Medicine, University of California, San Diego, La Jolla, California, USA

\section{Correspondence to}

Dr Shu-Hong Zhu, Moores Cancer Center, University of California, San Diego, 9500 Gilman Drive, MC 0905, La Jolla, California 92093-0905, USA; szhu@ucsd.edu

Received 11 July 2011 Accepted 7 December 2011

\section{ABSTRACT}

This paper reviews the literature on smoking cessation interventions, with a focus on the last 20 years (1991 to 2010). These two decades witnessed major development in a wide range of cessation interventions, from pharmacotherapy to tobacco price increases. It was expected that these interventions would work conjointly to increase the cessation rate on the population level. This paper examines population data from the USA, from 1991 to 2010, using the National Health Interview Surveys. Results indicate there is no consistent trend of increase in the population cessation rate over the last two decades. Various explanations are presented for this lack of improvement, and the key concept of impact = effectiveness $x$ reach is critically examined. Finally, it suggests that the field of cessation has focused so much on developing and promoting interventions to improve smokers' odds of success that it has largely neglected to investigate how to get more smokers to try to quit and to try more frequently. Future research should examine whether increasing the rate of quit attempts would be key to improving the population cessation rate.

\section{INTRODUCTION}

Quitting smoking has significant health benefits for current smokers. ${ }^{12}$ Interventions that can increase the smoking cessation rate on the population level will save many lives. ${ }^{2}{ }^{3}$

For any intervention to have a noticeable impact on the cessation rate at the population level, it must be effective and must reach a sufficient proportion of the smoking population. All things being equal, the population impact of an intervention is the product of its effectiveness and reach (impact $=$ effectiveness $\times$ reach). Historically, the cessation field has focused on developing effective interventions. It implicitly assumes that smokers will take advantage of a new treatment once it is developed and proven effective, and that the effectiveness of a treatment tested in a clinical trial will translate directly into a population effect; all that is needed is to get more smokers to use the intervention. ${ }^{4} 5$

This focus on developing effective treatments has produced impressive results. The last two decades have seen significant progress in this area. ${ }^{4} 6$ However, a corresponding increase in the population cessation rate has not been reported. This apparent lack of correspondence naturally raises questions. This paper addresses a few of them.
We focus on the last two decades (1991-2000 and 2001-2010), because this is when many new interventions with potential population effects were implemented. ${ }^{7}{ }^{8}$ We review the interventions that could be considered for population impact, then follow with an analysis of the data on population cessation rate using a national health survey in the USA. Finally, we examine various explanations for why the progress on population cessation is less than expected, and discuss the significant conceptual issues that the field has yet to address.

\section{POPULATION CESSATION: INTERVENTIONS CONSIDERED}

A 2000 Tobacco Control monograph considered a list of cessation interventions for their potential population effects. ${ }^{8}$ Table 1 updates the list and groups the interventions into two categories: those designed primarily as cessation interventions, such as pharmacotherapy, and those that have cessation as a secondary aim. For example, secondhand smoke policies were designed to protect non-smokers from exposure to cigarette smoke, and were later discovered to have an effect on cessation. Media campaigns belong to both: some focus on cessation while others convey a general anti-smoking message.

Within category I, the interventions are arranged according to the assumed specificity of their mechanisms. Pharmacotherapy tops the list because each medication is thought to have a specific pharmacological mechanism, and their differential effects are attributable to their respective mechanisms. Moving down the list, treatment intensity lessens, and so does the mechanistic claim. Behavioural interventions tend to be multicomponent, making it harder to isolate specific mechanisms of particular elements. Tests of new behavioural interventions, however, generally employ the same rigorous methodology as that of new medications, namely randomised controlled trials.

Moving down the list in category I, the interventions focus more on reaching a representative sample of smokers and a greater proportion of them, and less on achieving a strong effect per smoker. The assumption is that the small effect will accumulate if the interventions are delivered continually.

Interventions in category II generally have greater reach than those in category I and may thus have more of a claim to population effects, though they are not designed primarily as cessation 
Table 1 Primary and secondary cessation interventions

\begin{tabular}{ll}
\hline Category I: primary & Category II: secondary \\
\hline Pharmacotherapy & Policy for secondhand smoking \\
Quitlines & Tobacco price increases \\
Technology-based interventions & \\
Healthcare providers/system & \\
Employer-based programmes & \\
Media (cessation focused) & Media (general anti-smoking) \\
\hline
\end{tabular}

interventions. Studies reporting effects for these interventions, however, tend to rely on historical analysis rather than randomised controlled trials.

Interventions in table 1 have either been disseminated to a sizeable proportion of the smoking population or they have the potential to be. The review considers both their effectiveness and their reach.

\section{Pharmacotherapy}

Pharmacotherapies such as nicotine patches are recommended as first-line quit-smoking aids in clinical practice guidelines. ${ }^{4} 9$ Before 1992, nicotine gum was the main cessation medication. Patches came on the market in late 1991, creating much excitement. ${ }^{10}$ In 1996, gum and patches were approved as overthe-counter drugs, significantly increasing their use by smokers. ${ }^{11}$ Later, other forms of nicotine replacement therapy (NRT) were developed. The antidepressant bupropion was proven an effective cessation aid. Varenicline, a nicotinic receptor partial agonist, became a popular prescription medication in 2006. Meta-analyses have found averaged ORs of 1.58 for NRTs, ${ }^{12} 1.69$ for buproprion, ${ }^{13}$ and 2.31 for varenicline. ${ }^{14}$

Three main factors have influenced medication use: healthcare provider interest, cost and marketing efforts. Healthcare providers have been urged to do more to help smokers quit, ${ }^{4} 15-18$ policies to cover medication costs have expanded, ${ }^{19} 20$ and pharmaceutical companies' marketing efforts have been substantial. ${ }^{21}$

Data from the USA and UK indicate that use of cessation medications has increased substantially since patches became available. $^{22}$ A 2003 US survey found that among those who made a quit attempt in the previous 12 months, 32\% used medications, ${ }^{22}$ compared to about $6 \%$ in $1992 .{ }^{23}$ In the UK, the rate of medication use among those who made a quit attempt increased from $28 \%$ in 1999 to $61 \%$ in $2002 .{ }^{20}$ The dramatic increase was driven by a change in national policy regarding coverage of cessation medications. ${ }^{20}$

\section{Quitlines}

Quitlines, as an evidence-based treatment, came to be used by large numbers of smokers at about the same time the nicotine patch was introduced. ${ }^{24}$ In 1992, the first state-wide quitline was established in California using an experimentally validated counselling protocol. By 2004, most high-income countries had implemented quitlines as state-wide, regional, or national services. ${ }^{24}$ Multiple practice guidelines ${ }^{49} 25$ recommend quitlines as an accessible behavioural counselling service.

As with medications, quitline use is influenced by promotional efforts. $^{26-29}$ Unlike medications, which are promoted by pharmaceutical companies and healthcare systems, quitlines are generally promoted by public health agencies. Promotional budgets vary significantly, and with them quitline use rates. A 2005 US survey found that use rates across state quitlines ranged from $0.01 \%$ to $4.28 \%$ of smokers, with an average rate of about $1 \%{ }^{30}$
Most quitlines are components of larger tobacco control programmes rather than standalone clinical services. ${ }^{24}$ Thus, quitlines have grown more with the development of the tobacco control movement and less with changes in the addiction counselling field. ${ }^{31}$ For example, quitlines may be promoted when a state announces a new secondhand smoke policy or tax increase. $^{27} 32$ Quitlines often feature in anti-smoking media campaigns. ${ }^{33}$ More recently, they feature in initiatives to motivate healthcare providers to promote cessation. ${ }^{18} 34-36$

Probably the most significant recent development for quitlines is the trend to require a quitline number on cigarette packs along with graphic warning labels, ${ }^{37-42}$ dramatically expanding the reach of the quitting message. In countries that have implemented the programme, quitline call volume has significantly increased. $^{37} 38$ 40-42 More importantly, the quitline number reminds smokers that they should quit. The potential population impact of including quitline numbers on cigarette packs deserves careful study.

\section{Technology-based interventions}

The internet, cell phones and other mobile electronic devices have opened up new possibilities for smokers seeking cessation assistance. For example, $80 \%$ of Americans seek health-related information on the internet, ${ }^{43}$ and $9 \%$ of all internet users have searched for information on how to quit smoking. ${ }^{44}$ The reach of technology-based interventions is potentially high.

Evidence for the effectiveness of such interventions, however, is inconsistent. ${ }^{45}$ This is partly due to methodological challenges: it is difficult to ensure a control group in which participants do not use other cessation websites. Efforts to show difference in cessation outcomes for websites with different designs have not been successful. ${ }^{46}$ Some studies have reported positive results in which tailored materials are proactively delivered from the intervention site. ${ }^{47} 48$

Texting is another intervention that can be delivered proactively. Some studies have reported positive results. ${ }^{49} 50$ Others have used multiple components (email, web pages, text messages, calls) and found a positive effect. ${ }^{51} 52$ More research is anticipated, especially related to smart phone applications and social networking. The potential for population impact seems enhanced by the fact that these new modes of communication will soon be ubiquitous. ${ }^{53}$

\section{Healthcare providers and systems}

Doctors can play a key role in helping smokers quit. Assistance can include brief advice, prescribing medications and behavioural counselling. Brief doctor advice can increase quit rates among patients who smoke, ${ }^{4} 54$ and with follow-up the effect can be greater. ${ }^{4} 55$ This effect is not limited to doctors but includes other healthcare professionals. ${ }^{56-58}$

In the USA, the rate of smokers who report receiving advice to quit smoking increased significantly from about $27 \%$ in 1974 to $50 \%$ in $1987 .{ }^{16}$ Since then the rate has risen more slowly and remains under $60 \%{ }^{59} 60$

Many efforts have been made to increase doctor engagement in cessation. Recently, a model was developed with the aim of lightening the burden on doctors' time by having them refer their patients to quitlines. In some cases patient information is faxed directly to the quitline for follow-up. ${ }^{18}$ Several studies have demonstrated that linking doctor advice with quitline referral increases quit rates. ${ }^{34-36}$

A more comprehensive approach is to encourage entire healthcare systems to promote cessation, for example by expanding health benefits to cover medications and 
counselling. ${ }^{19} \mathrm{New}$ efforts capitalise on the movement to increase use of electronic medical records by adding a smoking module to the electronic medical records. ${ }^{61}$ This can help providers ask their patients' smoking status more routinely, which can increase quitting among the patient population. ${ }^{62}$

\section{Employer-based cessation programmes}

Modern worksite health promotion goes beyond concerns for worksite safety and encourages healthy lifestyles. ${ }^{63}$ Employersponsored programmes can potentially reach a large proportion of the work force.

Successful employer-based cessation programmes generally take two approaches, linking them to policies such as workplace smoking bans, ${ }^{64} 65$ and offering incentives to quit such as free NRT. ${ }^{66}{ }^{67}$ Learning from earlier studies on incentives, ${ }^{68}$ some employers combine monetary incentives with counselling. ${ }^{69} 70$ The proportion of employers who have adopted such comprehensive cessation programmes is not well documented.

\section{Media campaigns}

Paid advertisements and earned media both have the potential to reach a large segment of the population, and both can influence tobacco cessation. $^{71}$

Early work on community-wide interventions was the first to systematically use cessation-focused media campaigns. ${ }^{72-74}$ Starting in the 1990s, media campaigns were major components of successful state-wide tobacco control programmes in California and Massachusetts. ${ }^{71} 75$ These campaigns have included cessation-focused and general anti-smoking messages. ${ }^{76} 77$ They are considered effective in motivating smokers to quit and in changing social norms on smoking. ${ }^{71} 78$

Later studies on paid media included more content analysis. Emotional or personal adverts were found to be more effective than humorous adverts in encouraging quitting. ${ }^{71}$ Messages on the dangers of secondhand smoke to non-smokers can motivate smokers to quit just as much as those on the risks to smokers themselves. 71 79

Earned media can be just as influential. News coverage conveys a presumed importance of the issue being discussed while framing the public perception of it. ${ }^{71} 8081$ The most notable example is the extended discussion preceding the Master Settlement Agreement in the 1990s. ${ }^{82}$ Another is the earned media related to various Quit-and-Win campaigns. ${ }^{83}$ Rigorous evaluation is difficult, but earned media attention clearly contributed to Quit-and-Win's success in increasing quit attempts. $^{84} 85$

\section{Secondhand smoke policy}

Secondhand smoke policies are instituted to protect nonsmokers. Research has found that they also increase quitting among smokers. ${ }^{8}$ 86-89

Smoke-free policies have increased significantly in the last 20 years. ${ }^{90}$ As workplaces implement such policies, people adopt similar policies at home, ${ }^{86}$ 91-94 and effects of smoke-free homes on cessation are even more consistent than those of worksites. This is partly because these data are correlational. Worksite policies are imposed, while home bans may reflect smokers' own motivation to quit. Smoke-free homes should be promoted to help smokers quit, especially in countries where cessation services are limited. ${ }^{94}$

\section{Tobacco price increases}

Increased cigarette prices, usually due to tax increases, can decrease smoking prevalence. ${ }^{95-97}$ Higher prices deter non- smokers from starting to smoke $e^{98}$ and lead current smokers to reduce consumption or quit completely. ${ }^{97}$ 99-101

In the USA, cigarette prices have increased over the last two decades, though the real price (adjusted for the changing value of dollars) actually decreased between 2002 and 2006 before rising again. ${ }^{90}$ States increased taxes at different times, providing an opportunity to test the effects of price on smokers' behaviour. A consistent finding is that rising prices lead to reduced consumption. ${ }^{27} 77^{101-103}$ The effect may be greater among lowincome smokers. ${ }^{104} 105$

Surveys have assessed what smokers do when prices increase. Many report price-avoidance strategies such as purchasing cheaper brands. ${ }^{100}$ Others report quitting. ${ }^{103}$ Some studies have found that more smokers attempt to quit in response to tax increases than to workplace smoking bans. ${ }^{103}$ Others have found increases in quitting activity when prices increase, such as calling quitlines. ${ }^{27}$ Secondhand smoke policies and price increases can work synergistically to encourage cessation, although the unique contribution of each is difficult to determine. ${ }^{99} 106$

\section{Summary of interventions considered}

The last two decades witnessed not just the development of various effective cessation interventions, but also major efforts to increase their reach. ${ }^{80} 107$ For example, successes in pharmacotherapy research have been accompanied by clinical guidelines urging use of the new treatments and direct-toconsumer marketing. ${ }^{421}$ In the USA and elsewhere, secondhand smoke policies and cigarette prices have both increased. ${ }^{90}$ An expected outcome of these developments is that they would conjointly increase the cessation rate at the population level.

\section{POPULATION CESSATION RATE IN THE USA IN THE LAST TWO DECADES}

In the USA, the National Health Interview Survey (NHIS) has assessed smoking cessation annually since 1991 (except 1996). A detailed survey methodology can be found on the NHIS website. $^{108}$

Figure 1 presents NHIS data from 1991 to 2010, weighted to reflect the population in each survey year. It shows the annual cessation rate, defined as the percentage of smokers who quit smoking for at least 3 months in the past year. The 1993 NHIS did not assess the length of quitting, so is not included. The 1992 data were adjusted to account for missing data due to a skip pattern error in survey implementation.

The top panel presents the annual cessation rate for all smokers and the bottom panel for white non-Hispanic smokers. Focusing on a single large ethnic group helps to avoid potential confounding due to the changing ethnic composition in the USA. Quit rates for all smokers and white smokers, however, were very close for every year. They are plotted separately for ease of visual inspection.

Cessation rates vary from year to year, but there is no significant upward trend for the whole period. Attempts to fit a linear trend for these two panels of data (weighted by the sample size for each survey year) found the slopes are slightly negative but not statistically significantly different from zero $(\mathrm{r}=-0.02, \mathrm{p}=0.94$, all smokers, and $\mathrm{r}=-0.17, \mathrm{p}=0.50$ for white smokers).

A single linear model for the whole period, however, has a poor fit $\left(R^{2}=0.005, p=0.78\right.$ for the linear model for all smokers, and $R^{2}=0.03, p=0.49$ for white smokers), suggesting that using a single linear model for the whole period is inappropriate. One could use the year 2000 as a break point to fit various higher 

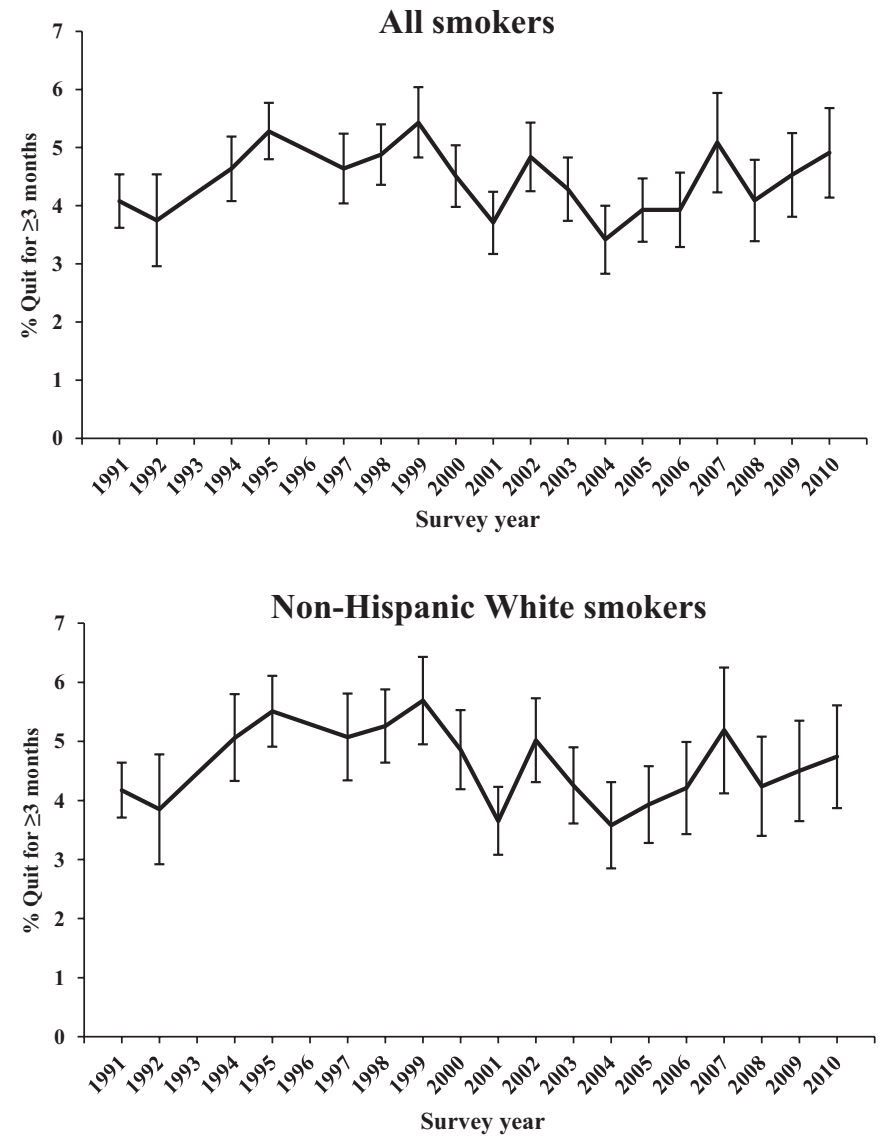

Figure 1 Annual cessation rates for US smokers from 1991 to 2010. The top panel is for smokers of all ethnicities, and the bottom panel is for non-Hispanic white smokers. Data are from the National Health Interview Survey (NHIS). Responses from proxies are not included. The 1992 data were adjusted by imputation to account for missing values caused by skip pattern errors. Results were weighted to be representative of the national population of adults aged 18 years and older in each survey year.

order functions. Using 2000 as a knot in model fitting is a reasonable choice because it was shortly after the Master Settlement Agreement (MSA), which led to a large price increase and the establishment of many state tobacco programmes. However, no obvious higher order functions fit well. (Space limitations do not permit a full description of the modelling effort, but interested readers may contact the authors for details.) Although certain years have higher cessation rates than others, there is no obvious periodicity or predictability in these rates. Statistically speaking, there is no trend.

Most importantly, there is no consistent upward trend, which would be expected given the various interventions that have been implemented in the USA over the last two decades. This is a perplexing result.

It is tempting to look only at the time between 1991 and 1999, when a significant positive linear trend can be found. This might even be a true trend. However, there is no obvious explanation for the drop in cessation after 1999. In fact, many state tobacco control programmes started to take effect around 2000 , with money received from the MSA. ${ }^{109}$ Since no a priori justification exists for fitting one function for the period ending at 1999 and a separate function after that, the appropriate conclusion is that there is no function that fits the whole period of 1991-2010.
On average, the annual cessation rate (defined as quitting for at least 3 months) for all US smokers over the whole period is $4.4 \%$. From 1991 to 2000, the mean quit rate is $4.7 \%$ and from 2001 to 2010 the mean is $4.2 \%$. The two rates are not statistically different.

\section{EXPLANATIONS FOR THE LACK OF IMPROVEMENT}

The data in figure 1 call for rethinking population cessation. Although the data are from one country, they present challenges for the cessation field in general. The field has focused on developing and promoting effective treatments, assuming that most smokers will take advantage of them and that as more smokers use them the population cessation rate will rise.

\section{A problem of reach?}

An immediate response to the data shown in figure 1 is to attribute the lack of improvement in population cessation rates to an insufficient number of smokers using treatment. A rate of treatment use that would be considered sufficient has not been articulated. However, it has long been said that use is too low. ${ }^{4} 5110111$ From a rational perspective, smokers who want to quit should use treatment because it increases their chance of success. That many do not is considered a problem. Thus, there has been much emphasis on increasing consumer demand for cessation treatments. ${ }^{112}$

But it is not clear that the use rate is too low in all cases. Use of pharmacotherapy has increased significantly in the USA over the last two decades. Figure 2 shows the data from four NHIS surveys (1992, 2000, 2005 and 2010) in which smokers' use of cessation medications was assessed. Use (as shown in the first cluster of columns) increased significantly from 1992 to 2010. By $2000,22.1 \%$ of people making quit attempts used medications (25.8\% for white smokers). This further increased to $31.2 \%$ by 2010 (36.4\% for white smokers). However, there is no corresponding incremental increase in the 3-month quit rate (as in the second cluster). The quit rate varies also, but it corresponds more to changes in the quit attempt rate (as in the third cluster) than to changes in the use of cessation medications.

Usage data from the UK are even more instructive. In the UK, medication use has changed more dramatically and in a shorter period. From 1999 to 2001, the proportion of quit attempts that were associated with use of cessation medications jumped from $28 \%$ to $61 \%$ (due to a change in national health policy to cover medications) ${ }^{20}$ A corresponding change was projected but not found in the population cessation rate for that period. ${ }^{20} 23113$

Some have argued that the lack of improvement in the population cessation rate means that the treatment approach is not the main route to increasing population cessation and that this approach may even need to be abandoned. ${ }^{114}$ This argument has merit. However, the unchanging quit rate is not necessarily proof that treatment has been useless. The same argument could be made against other approaches such as tax increases and secondhand smoke campaigns. In the USA, there have been significant increases in cigarette prices and in smoke-free policies over the last 20 years..$^{90}$ The price and policy changes are even more pronounced in the latter half than in the first half of the period examined in this study. Yet there is no consistent upward trend in cessation for the two decades, and the average cessation rate for the latter was slightly lower than that for the first half, $4.2 \%$ versus $4.7 \%$.

It appears, therefore, that improving the population cessation rate is not simply a matter of increasing the reach of interventions (whether treatments or policies) previously shown to be effective. Increasing reach may be necessary but not sufficient. 

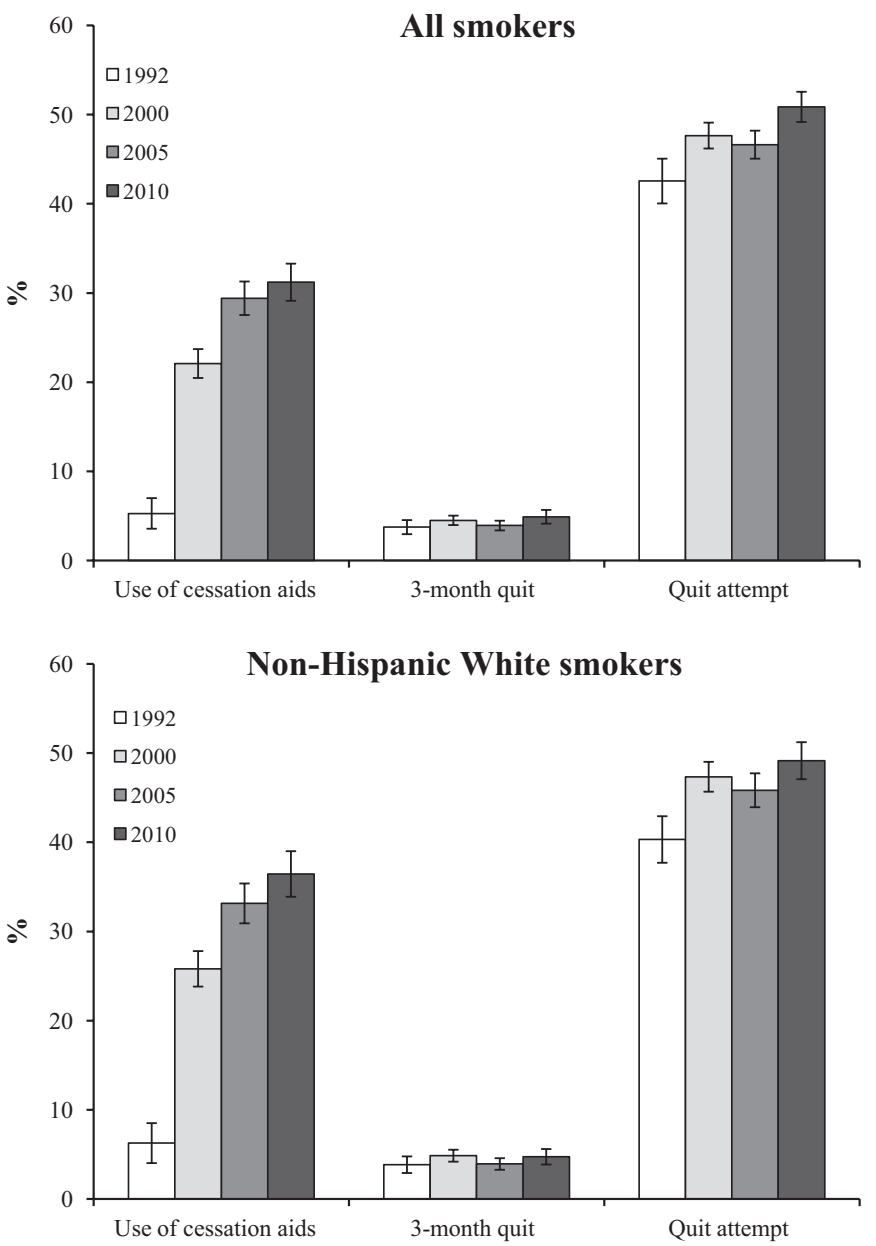

Figure 2 Percentage of smokers using cessation aids, percentage achieving abstinence for 3 months and percentage making a quit attempt (the 1992 survey only asked about nicotine gum use). Top panel is for smokers of all ethnicities and bottom panel is for non-Hispanic white smokers. Data are from the National Health Information Survey (NHIS) in 1992, 2000, 2005 and 2010. Results were weighted to be representative of the national population of adults aged 18 years and older in each survey year.

\section{A problem of effectiveness?}

Another interpretation of these data is that the interventions are not really effective. If true, it would render the increased reach irrelevant. Since most of the interventions (especially pharmacotherapy) were proven effective with rigorous experimental designs, one may suspect that they lost effectiveness when translated into real-world applications. ${ }^{115}$ There are many reasons why treatments tested in controlled settings might lose their effectiveness in real-world implementation. ${ }^{116}$ But such a position is vigorously contested as unreasonable in the case of cessation medications. ${ }^{117}$ Studies have reported that NRT continued to outperform placebos when it went over-thecounter. ${ }^{118}$ Thus, for smokers who use medications, the medications helped. The question is why a significant increase in pharmacotherapy use was not associated with an increase in population cessation, as was projected. ${ }^{11}$

Moreover, the loss-of-effectiveness argument does not apply to some interventions. Effects of taxes on cessation are studied in the context of implementation ${ }^{103}$; there is no additional step of translation. It is possible that tax increases have different effects on smoking cessation and smoking uptake. Tax increases may have an initial effect by encouraging some smokers to quit, while having no effect on those who continue to smoke after the tax increase. In this sense, the tax may lose effectiveness over time.

The most serious problem is as follows: all interventions reviewed in the earlier section have been reported as having identifiable, unique effects on cessation. Even if their real-world effects were only half those reported in the original studies, the combined effect of all interventions should be detectable on the population level because their combined reach is not negligible and has increased over the last two decades. This argument assumes that interventions do not cancel out each other's effects when applied together in the real world. This is a reasonable assumption, although no study has tested it. Regardless, the fact that the combined effect cannot be predicted or detected on the population level (as shown in figure 1) raises the challenge to the field to a different level. It is more than an issue of the relative effectiveness of individual interventions. ${ }^{114} 119$ Even if one intervention has indeed lost its effect in real-world application, we still have the problem of interventions as a whole not producing a predictable effect. Apparently some factor is countering the expected population effects of these interventions, or the true effects of interventions are much smaller than reported.

\section{A hardening of the target?}

One explanation for the lack of a consistent upward trend over time as shown in figure 1 is that there is a hardening of the target. This refers to a hypothesised process in which smokers with higher probabilities of success quit first, which results over time in a greater proportion of smokers with lower probabilities of success among the remaining smokers. ${ }^{120}$ This means the base rate (ie, the rate of self-quitting without intervention) for population cessation is decreasing over time, cancelling out the combined effects of interventions, which would otherwise have produced an upward trend. If the target is indeed hardening, the fact that there is no general decline in the population cessation rate could be evidence that the interventions have had a positive effect.

This is an interesting and plausible hypothesis, but it is difficult to test. No study has quantified the effect size of the proposed hardening process or measured the slope of the decreasing base rate. The data pattern in figure 1 does not readily suggest a constant rate of hardening, if there is such a process, and the hypothesis is difficult to test if the rate of hardening is not constant.

\section{Caveats}

A few caveats are in order before further discussion. This paper is concerned with the smoking cessation rate, not smoking prevalence. The cessation rate is that proportion of smokers who quit, while smoking prevalence is the proportion of the entire population who smoke. An intervention could have an effect on prevalence, but not on cessation. Thus, there is no inherent contradiction in the smoking prevalence in the USA having declined over the last 20 years ${ }^{121}$ while the cessation rate remained unchanged. Neither is there a contradiction in the finding that the quit ratio increased during this period, ${ }^{122}$ because the quit ratio refers to the accumulated quit rate among ever-smokers while figure 1 presents the annual cessation rate of current smokers.

Also, figure 1 shows that the cessation rate has not increased in the USA from 1991 to 2010. This does not imply that the cessation rate in the USA has never changed. The US cessation rate was certainly higher in the 1990s than in the 1950s. ${ }^{123}$ It also does not imply that cessation rates from 1991 to 2010 have not changed in other countries, especially those in earlier stages of the tobacco epidemic. ${ }^{124}$ Our question is why the cessation 
rate has not improved in the USA in the last 20 years, a period when many effective interventions were developed and implemented with significant reach.

\section{A re-evaluation of impact $=$ effectiveness $\times$ reach}

The equation impact $=$ effectiveness $\times$ reach is a logical description of what needs to happen for an intervention to have population impact. It says nothing about what might happen when an intervention proven effective in a research trial is implemented in a real-world setting. Many smokers may be uninterested in the intervention, and aggressive promotion may be needed to ensure use, which means the intervention may be delivered to people different from those who participated in the original study. ${ }^{115} 116$ Of all potential differences relevant for behaviour change, the most significant is probably the motivation of participants, including whether they believe in the intervention. ${ }^{125}$ Research trials generally enrol those who are interested in the new intervention being tested. Such interest may not exist for those who usually do not seek help when attempting to change a health behaviour, or may be significantly less for potential participants when the intervention is no longer new. In other words, the effectiveness of an intervention may vary with its reach.

A more important issue is the possibility of unintended consequences in promoting interventions. For example, an overemphasis on the power of medications to help smokers quit may lead them to think they cannot quit without the medications, lowering self-efficacy and reducing the base rate of quitting. Such a reduction is not normally detected by clinical trials, which are usually designed to compare a treatment medication against its placebo, not one promotional message against another. Any reduction in base rate due to promotion would occur in treatment and placebo conditions, making the relative difference in outcomes unchanged (or even making it larger). In this scenario, medications would continue to be shown to be effective for those who use them, while an increase in the rate of use may not lead to an increase in cessation on the population level.

Unintended consequences could occur with other interventions. For example, when a cigarette tax is increased, some smokers respond by quitting and others by reducing consumption. Those who respond by reducing consumption may feel that they have taken a positive step and have less desire to quit. If the remaining smokers are satisfied with their progress enough to stop trying to quit completely, the cessation rate may actually decrease a few years after the tax increase.

If any of these unintended consequences occur, then the logically correct equation, impact $=$ effectiveness $\times$ reach, is no longer a sure guide for population cessation because the effort to increase reach may negatively affect the total impact of the intervention in a way that is not easily detected. Outreach may not change the relative effectiveness of the intervention, but it can affect the base rate of quitting. If the effect on the base rate is negative, then it can result in a situation in which reach is increased with no corresponding increase in the population cessation rate. To date, few have examined empirically whether unintended consequences occur, a remarkable gap in the cessation literature.

The lack of clear progress in population cessation over the last two decades suggests that the field needs to design studies that will more specifically assess the effects of interventions on the population level rather than relying on logical arguments and extrapolating from clinical studies. The following section proposes one useful starting point.

\section{The importance of quit attempts}

It has been suggested that the quit attempt rate is a good indicator of population cessation, better than measures such as the usage rate of cessation aids. ${ }^{23} 126$ At the most basic level, the quit attempt rate is the best indicator of motivation to quit in a given population. There are several applications of this idea to the current discussion.

Figure 3 shows the rate of quit attempts, defined as quitting for at least $24 \mathrm{~h}$, among US smokers from 1991 to 2010 . The quit attempt rate varies over time but predicts the annual cessation rate shown in figure $1(\mathrm{r}=0.59, \mathrm{p}<0.01$ for all smokers, $\mathrm{r}=0.49$, $\mathrm{p}<0.05$ for white smokers). Most importantly, figure 3 shows that the quit attempt rate has remained close to but below $50 \%$ in most cases. All the interventions implemented in the last
Figure 3 Percentage of smokers making a quit attempt, for smokers of all ethnicities and non-Hispanic white smokers. Data are from the National Health Interview Survey. The 1992 data were adjusted by imputation to account for missing values caused by skip pattern errors. From 1991 to 1995, only daily smokers were asked whether they had made a quit attempt. Results were weighted to be representative of the national population of adults aged 18 years and older in each survey year.

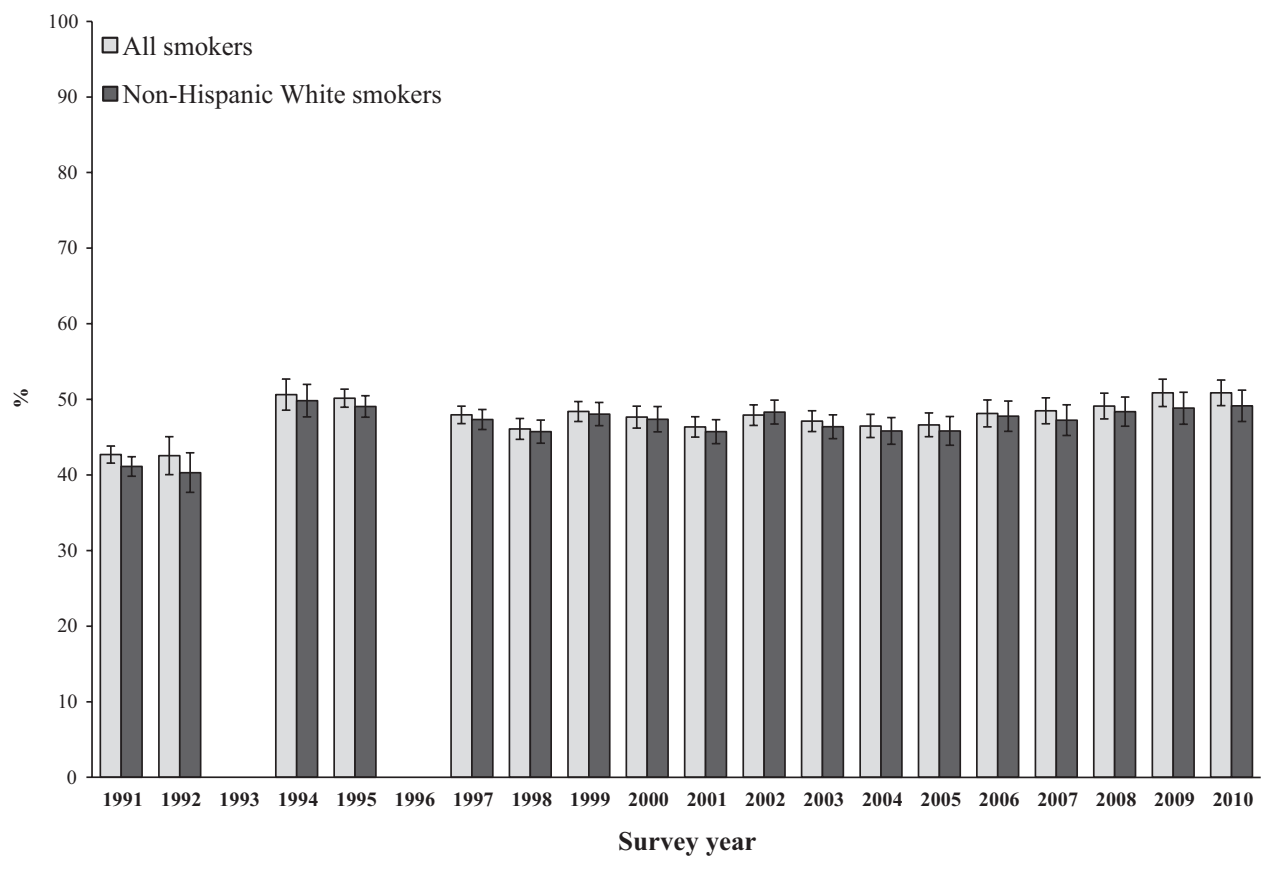




\section{What this paper adds}

The US national data (1991-2010) shows no consistent trend of increase in the population cessation rate during this twodecade period.

- This study explored various explanations for this lack of improvement and critically examined the key concept that an intervention's impact $=$ effectiveness $\times$ reach.

- This study points out that the cessation field has focused so much on developing interventions to improve smokers' odds of success that it has largely neglected to investigate how to get more smokers to try to quit and to try more frequently.

20 years have yet to move the attempt rate higher than $50 \%$. In that light it is less surprising that the annual cessation rate has not risen during this period.

The quit attempt rate could also be an indicator of unintended consequences when an intervention is promoted among smokers. An example is the UK policy change encouraging smokers to use cessation aids. The policy change did not result in an increase in the population cessation rate, even though medication usage significantly increased. ${ }^{20} 113$ This may be due in part to the fact that the quit attempt rate did not increase. In one case, the policy change was associated with a significant decrease in the quit attempt rate, ${ }^{113}{ }^{127}$ suggesting a possible negative impact on the base rate for quitting. The same concept can be applied to measuring the promotion of other interventions, such as those that induce smokers to reduce consumption. If the quit attempt rate decreases while consumption declines, there is a good chance that there will be unintended effects on cessation.

Finally, it might seem obvious that smokers must first try to quit before they can succeed, making the importance of quit attempts self-evident. However, the field of cessation has focused so much on developing interventions to improve smokers' odds of success when they attempt to quit that it has largely neglected to investigate how to get more smokers to try to quit and to try more frequently. ${ }^{127}$ Future research should test whether increasing the rate of quit attempts is key to improving cessation on the population level.

Acknowledgements We would like to thank Sharon Cummins, Gary Tedeschi, Christopher Anderson and Erik Augustson for helpful comments on earlier drafts of the paper.

Funding This work was supported in part by a grant from National Cancer Institute U01 CA154280. The views expressed are entirely those of the authors and do not necessarily reflect those of National Cancer Institute.

Competing interests $\mathrm{S}-\mathrm{HZ}, \mathrm{ML}, \mathrm{Y}-\mathrm{LZ}, \mathrm{AG}$ and TW conduct tobacco control research supported by funding from government agencies such as the US National Institute of Health $(\mathrm{NIH})$ and the California Department of Public Health. They have no other conflict of interest to declare.

Ethics approval This study has been approved by the ethics committee of the institutional review board, University of California, San Diego, Human Research Protection Program.

Provenance and peer review Commissioned; externally peer reviewed

\section{REFERENCES}

1. Office of the Surgeon General, United States Public Health Service. The Health Benefits of Smoking Cessation: A Report of the Surgeon General. Bethesda, MD: United States Public Health Service, Office on Smoking and Health, 1990.
2. Doll R, Peto R, Boreham J, et al. Mortality in relation to smoking: 50 years' observations on male British doctors. BMJ 2004;328:1519-28.

3. Taylor DH, Hasselblad V, Henley SJ, et al. Benefits of smoking cessation for longevity. Am J Public Health 2002:92:990-6.

4. Fiore MC, Jaen CR, Baker TB, et al, eds. Treating Tobacco Use and Dependence: Clinical Practice Guideline. Rockville, MD: U.S. Department of Health and Human Services, Public Health Service, 2008.

5. Abrams DB, Graham AL, Levy DT, et al. Boosting population quits through evidence-based cessation treatment and policy. Am J Prev Med 2010;38. S351-63.

6. Aveyard P, Raw M. Improving smoking cessation approaches at the individual level. Tob Control 2012:21:252-7.

7. Lichtenstein E. From rapid smoking to the internet: five decades of cessation research. Nicotine Tob Res 2002;4:139-45.

8. Shopland DR, Burns DM, Amacher RH, et al, eds. Population Based Smoking Cessation: Proceedings of a Conference on What Works to Influence Cessation in the General Population. Smoking and Tobacco Control Monograph 12. Bethesda, MD: US Department of Health and Human Services, Public Health Service, National Institutes of Health, National Cancer Institute, 2000.

9. National Institute for Health and Clinical Excellence, ed. Smoking cessation services in primary care, pharmacies, local authorities and workplaces, particularly for manual working groups, pregnant women and hard to reach communities. NICE Public Health Guidance 10. London: National Institute for Health and Clinical Excellence, 2008.

10. Fiore MC, Smith SS, Jorenby DE, et al. The effectiveness of the nicotine patch for smoking cessation. JAMA 1994;271:1940-7.

11. Shiffman S, Gitchell J, Pinney JM, et al. Public health benefit of over-the-counter nicotine medications. Tob Control 1997:6:306-10.

12. Stead LF, Perera R, Mant D, et al. Nicotine replacement therapy for smoking cessation. Cochrane Database Syst Rev 2008;(1):CD000146.

13. Hughes JR, Stead LF, Lancaster T. Antidepressants for smoking cessation. Cochrane Database Syst Rev 2007;(1):CD000031.

14. Cahill K, Stead LF, Lancaster T. Nicotine receptor partial agonists for smoking cessation. Cochrane Database Syst Rev 2011;(2):CD006103.

15. Russell MA, Wilson C, Taylor C, et al. Effect of general-practitioners advice agains smoking. Br Med J 1979;2:231-5.

16. Gilpin E, Pierce J, Goodman J, et al. Trends in physicians' giving advice to stop smoking, United States, 1974-1987. Tob Control 1992;1:31-6.

17. Shopland DR, Burns DM, Cohen SJ, et al, eds. Tobacco and the Clinician: Interventions for Medical and Dental Practice. Smoking and Tobacco Control Monograph 5. Bethesda, MD: US Department of Health and Human Services, Public Health Service, National Institutes of Health, National Cancer Institute, 1994

18. Schroeder SA. What to do with a patient who smokes. JAMA 2005:294 482-7.

19. Curry SJ, Grothaus LC, McAfee T, et al. Use and cost effectiveness of smokingcessation services under four insurance plans in a health maintenance organization. N Engl J Med 1998;339:673-9.

20. West R, DiMarino ME, Gitchell J, et al. Impact of UK policy initiatives on use of medicines to aid smoking cessation. Tob Control 2005;14:166-71.

21. Tauras JA, Chaloupka FJ, Emery S. The impact of advertising on nicotine replacement therapy demand. Soc Sci Med 2005;60:2351-8.

22. Shiffman S, Brockwell SE, Pillitteri JL, et al. Use of smoking-cessation treatments in the United States. Am J Prev Med 2008;34:102-11.

23. Zhu S. Increasing cessation in the population: quit attempts vs unsuccessful quit attempts. Paper presented at: $13^{\text {th }}$ World Conference on Tobacco or Health; 12-15 Jul, Washington, DC, 2006.

24. Anderson CM, Zhu SH. Tobacco quitlines: looking back and looking ahead. Tob Control 2007:16:i81-6.

25. World Health Organization. WHO Report on the Global Tobacco Epidemic, 2008 The MPOWER Package. Geneva: World Health Organization, 2008.

26. Miller CL, Wakefield M, Roberts L. Uptake and effectiveness of the Australian telephone Quitline service in the context of a mass media campaign. Tob Control 2003;12:iï3-8.

27. Sheffer MA, Redmond LA, Kobinsky KH, et al. Creating a perfect storm to increase consumer demand for Wisconsin's Tobacco Quitline. Am J Prev Med 2010;38: S343-6.

28. Miller N, Frieden TR, Liu SY, et al. Effectiveness of a large-scale distribution programme of free nicotine patches: a prospective evaluation. Lancet 2005; $365: 1849-54$

29. Zhu S, Gardiner P, Cummins S, et al. Quitline utilization rates of African-American and white smokers: the California experience. Am J Health Promot 2011; 25:S51-8.

30. Cummins SE, Bailey L, Campbell S, et al. Tobacco cessation quitlines in North America: a descriptive study. Tob Control 2007:16:i9-15.

31. Beyer EJ, Keller PA, Bailey LA, et al. State-level factors influencing tobacco cessation quitline spending in 2008. Prev Med 2010;51:191-2.

32. Harwell TS, Lee L, Haugland C, et al. Utilization of a tobacco quit line prior to and after a tobacco tax increase. J Public Health Manag Pract 2007;13 637-41.

33. Hill D, Carroll T. Australia's national tobacco campaign. Tob Control 2003;12 iï-14. 
34. An LC, Zhu S, Nelson DB, et al. Benefits of telephone care over primary care for smoking cessation: a randomized trial. Arch Intern Med 2006;166:536-42.

35. Borland R, Balmford J, Bishop N, et al. In-practice management versus quitline referral for enhancing smoking cessation in general practice: a cluster randomized trial. Fam Pract 2008;25:382-9.

36. Rothemich SF, Woolf SH, Johnson RE, et al. Promoting primary care smokingcessation support with quitlines: the QuitLink Randomized Controlled Trial. Am J Prev Med 2010;38:367-74.

37. Willemsen MC, Simons C, Zeeman G. Impact of the new EU health warnings on the Dutch quit line. Tob Control 2002;11:381-2.

38. Miller CL, Hill DJ, Quester PG, et al. Impact on the Australian Quitline of new graphic cigarette pack warnings including the Quitline number. Tob Control 2009:18:235-7.

39. U.S. Department of Health and Human Services. FDA Unveils Final Cigarette Warning Labe/s. 2011. http://www.hhs.gov/news/press/2011pres/06/20110621a. html (accessed 5 Dec 2011)

40. Li J, Grigg M. New Zealand: new graphic warnings encourage registrations with the quitline. Tob Control 2009:18:72.

41. Hsu P, Chang C. Taiwan Smokers' Helpline. Paper pesented at: 2011 Asian Pacific Quitline Workshop: 7-8 Jun, Goyang. Republic of Korea 2011

42. Yunibhand J. Thailand Report on Quitline Activities. Paper presented at: 2011 Asian Pacific Quitline Workshop; 7-8 Jun, Goyang, Republic of Korea 2011

43. Fox S, ed. The Social Life of Health Information, 2011. Pew Internet \& American Life Project. http://www.pewinternet.org/Reports/2011/Social-Life-of-Health-Info/ Summary-of-Findings.aspx (accessed 20 Dec 2011).

44. Cobb NK, Graham AL. Characterizing internet searchers of smoking cessation information. J Med Internet Res 2006;8:e17.

45. Civljak M, Sheikh A, Stead LF, et al. Internet-based interventions for smoking cessation. Cochrane Database Syst Rev 2010;(9):CD007078.

46. Rabius V, Pike KJ, Wiatrek D, et al. Comparing internet assistance for smoking cessation: 13-month follow-up of a six-arm randomized controlled trial. J Med Internet Res 2008;10:e45.

47. Strecher VJ, Shiffman S, West R. Randomized controlled trial of a web-based computer-tailored smoking cessation program as a supplement to nicotine patch therapy. Addiction 2005;100:682-8.

48. Te Poel F, Bolman C, Reubsaet A, et al. Efficacy of a single computer-tailored e-mail for smoking cessation: results after 6 months. Health Educ Res 2009;24:930-40.

49. Rodgers A, Corbett T, Bramley D, et al. Do u smoke after txt? Results of a randomised trial of smoking cessation using mobile phone text messaging. Tob Control 2005;14:255-61.

50. Free C, Knight R, Robertson S, et al. Smoking cessation support delivered via mobile phone text messaging (txt2stop): a single-blind, randomised trial. Lancet 2011:378:49-55

51. Brendryen H, Kraft P. Happy ending: a randomized controlled trial of a digital multimedia smoking cessation intervention. Addiction 2008;103:478-84.

52. Brendryen $\mathbf{H}$, Drozd F, Kraft P. A digital smoking cessation program delivered through internet and cell phone without nicotine replacement (happy ending): randomized controlled trial. J Med Internet Res 2008;10:e51.

53. Nielsen News. In US, Smartphones Now Majority of New Cellphone Purchases. 2011. http://blog.nielsen.com/nielsenwire/online mobile/in-us-smartphones-nowmajority-of-new-cellphone-purchases/ (accessed 5 Dec 2011).

54. Ockene JK, Edgerton EA, Teutsch SM, et al. Integrating evidence-based clinical and community strategies to improve health. Am J Prev Med 2007;32: 244-52.

55. Aveyard P, Brown K, Saunders C, et al. Weekly versus basic smoking cessation support in primary care: a randomised controlled trial. Thorax 2007;62: 898-903.

56. Rice VH, Stead LF. Nursing interventions for smoking cessation. Cochrane Database Syst Rev 2008;(1):CD001188.

57. Bodner ME, Dean E. Advice as a smoking cessation strategy: a systematic review and implications for physical therapists. Physiother Theory Pract 2009;25:369-407.

58. Gordon JS, Andrews JA, Albert DA, et al. Tobacco cessation via public dental clinics: results of a randomized trial. Am J Public Health 2010:100:1307-12.

59. Lucan SC, Katz DL. Factors associated with smoking cessation counseling at clinical encounters: the Behavioral Risk Factor Surveillance System (BRFSS) 2000. Am J Health Promot 2006:21:16-23.

60. Centers for Disease Control and Prevention. Quitting smoking among adults-United States, 2001-2010. MMWR Morb Mortal Wkly Rep 2011;60:1513-19.

61. Boyle RG, Solberg LI, Fiore MC. Electronic medical records to increase the clinical treatment of tobacco dependence: a systematic review. Am J Prev Med 2010;39(6 Suppl 1):S77-82

62. Linder JA, Rigotti NA, Schneider LI, et al. An electronic health record-based intervention to improve tobacco treatment in primary care: a cluster-randomized controlled trial. Arch Intern Med 2009;169:781-7.

63. Hymel PA, Loeppke RR, Baase CM, et al. Workplace health protection and promotion: a new pathway for a healthier-and safer-workforce. J Occup Environ Med 2011;53:695-702.

64. Nagelhout GE, Willemsen MC, de Vries $\mathrm{H}$. The population impact of smoke-free workplace and hospitality industry legislation on smoking behaviour. Findings from a national population survey. Addiction 2011;106:816-23.
65. Lopez MJ, Nebot M, Ramos P, et al. Can smoking cessation be successfully promoted among hospitality workers? Results of a pilot intervention. Occup Environ Med 2010;67:503-4.

66. Hotta K, Kinumi $\mathrm{K}$, Naito $\mathrm{K}$, et al. An intensive group therapy programme for smoking cessation using nicotine patch and internet mailing supports in a university setting. Int J Clin Pract 2007:61:1997-2001

67. Okechukwu CA, Krieger N, Sorensen G, et al. MassBuilt: effectiveness of an apprenticeship site-based smoking cessation intervention for unionized building trades workers. Cancer Causes Control 2009:20:887-94.

68. Glasgow RE, Hollis JF, Ary DV, et al. Results of a year-long incentives-based worksite smoking-cessation program. Addict Behav 1993;18:455-64.

69. Hennrikus DJ, Jeffery RW, Lando HA, et al. The SUCCESS Project: the effect of program format and incentives on participation and cessation in Worksite smoking cessation programs. Am J Public Health 2002:92:274-9.

70. Volpp KG, Troxel AB, Pauly MV, et al. A randomized, controlled trial of financial incentives for smoking cessation. N Engl J Med 2009;360 $699-709$

71. National Cancer Institute, ed. The role of the media in promoting and reducing tobacco use. Smoking and Tobacco Control Monograph 19. Bethesda, MD: US Department of Health and Human Services, Public Health Service, Nationa Institutes of Health, National Cancer Institute, 2008.

72. Egger G, Fitzgerald W, Frape G, et al. Results of large-scale media anti-smoking campaign in Australia: "North-Coast-Quit-For-Life" programme. Br Med J (Clin Res Ed) 1983;287:1125-8.

73. Fortmann SP, Taylor CB, Flora JA, et al. Changes in adult cigarette smoking prevalence after 5 years of community health education: the Stanford Five-City Project. Am J Epidemiol 1993;137:82-96.

74. Taylor SM, Ross NA, Cummings KM, et al. Community Intervention Trial for Smoking Cessation (COMMIT): changes in community attitudes toward cigarette smoking. Health Educ Res 1998;13:109-22.

75. Goldman LK, Glantz SA. Evaluation of antismoking advertising campaigns. JAMA 1998;279:772-7.

76. Stevens C. Designing an effective counteradvertising campaign-California. Cancer 1998:83:2736-41.

77. Biener L, Harris JE, Hamilton W. Impact of the Massachusetts tobacco control programme: population based trend analysis. BMJ 2000;321:351-4.

78. Cowling DW, Modayil MV, Stevens C. Assessing the relationship between ad volume and awareness of a tobacco education media campaign. Tob Control 2010:19:i37-42

79. Netemeyer RG, Andrews JC, Burton S. Effects of antismoking advertising-based beliefs on adult smokers' consideration of quitting. Am J Public Health 2005:95:1062-6.

80. Chapman S. The news on tobacco control: time to bring the background into the foreground. Tob Control 1999;8:237-9

81. Malone RE, Boyd E, Bero LA. Science in the news: journalists' constructions of passive smoking as a social problem. Soc Stud Sci 2000;30:713-35.

82. Lima JC, Siegel M. The tobacco settlement: an analysis of newspaper coverage of a national policy debate, 1997-98. Tob Control 1999;8:247-53.

83. Korhonen T, McAlister A, Laaksonen M, et al. International quit and win 1996: standardized evaluation in selected campaign countries. Prev Med 2000;31:742-51

84. Hahn EJ, Rayens MK, Warnick TA, et al. A controlled trial of a quit and win contest. Am J Health Promot 2005:20:117-26.

85. van Osch $\mathbf{L}$, Lechner $L$, Reubsaet $A$, et al. Optimizing the efficacy of smoking cessation contests: an exploration of determinants of successful quitting. Health Educ Res 2009:24:54-63.

86. Farkas AJ, Gilpin EA, Distefan JM, et al. The effects of household and workplace smoking restrictions on quitting behaviours. Tob Control 1999:8:261-5.

87. Glasgow RE, Cummings KM, Hyland A. Relationship of worksite smoking policy to changes in employee tobacco use: findings from COMMIT. Community Intervention Trial for Smoking Cessation. Tob Control 1997:6:S44.

88. Moskowitz JM, Lin ZH, Hudes ES. The impact of workplace smoking ordinances in California on smoking cessation. Am J Public Health 2000;90:757-61.

89. Fichtenberg CM, Glantz SA. Effect of smoke-free workplaces on smoking behaviour: systematic review. BMJ 2002;325:188-91.

90. Chaloupka FJ, Levy D, Huang J. The Impact of Tax and Smoke-Free Air Policy Changes. Princeton, NJ: Robert Wood Johnson Foundation Tobacco Retrospective Series, 2011.

91. Hyland A, Higbee C, Travers MJ, et al. Smoke-free homes and smoking cessation and relapse in a longitudinal population of adults. Nicotine Tob Res 2009:11:614-18.

92. Jarvis MJ, Mindell J, Gilmore A et al. Smoke-free homes in England: prevalence, trends and validation by cotinine in children. Tob Control 2009; 18:491-5

93. Cheng K, Glantz SA, Lightwood JM. Association between smokefree laws and voluntary smokefree-home rules. Am J Prev Med 2011;41:566-72.

94. Gao J, Zheng P, Gao J, et al. Workplace smoking policies and their association with male employees' smoking behaviours: a cross-sectional survey in one company in China. Tob Control 2011;20:131-6.

95. Hopkins DP, Briss PA, Ricard CJ, et al. Reviews of evidence regarding interventions to reduce tobacco use and exposure to environmental tobacco smoke. Am J Prev Med 2001;20:16-66. 
96. Forster $\mathbf{M}$, Jones $\mathrm{AM}$. The role of tobacco taxes in starting and quitting smoking: duration analysis of British data. J R Stat Soc Ser A 2001;164:517-47.

97. Chaloupka FJ, Warner KE, eds. The Economics of Smoking. Working Paper No. 7047. Cambridge, MA: National Bureau of Economic Research, 1999.

98. Chaloupka FJ, Wechsler H. Price, tobacco control policies and smoking among young adults. J Health Econ 1997:16:359-73.

99. Scollo M, Younie S, Wakefield M, et al. Impact of tobacco tax reforms on tobacco prices and tobacco use in Australia. Tob Control 2003;12:ii59-66.

100. Hyland A, Bauer JE, Li 0 , et al. Higher cigarette prices influence cigarette purchase patterns. Tob Control 2005;14:86-92.

101. Pierce JP, Gilpin EA, Emery SL, et al. Has the California tobacco control program reduced smoking? JAMA 1998;280:893-9.

102. Lightwood J, Glantz S. Effect of the Arizona tobacco control program on cigarette consumption and healthcare expenditures. Soc Sci Med 2011;72:166-72.

103. Frieden TR, Mostashari F, Kerker BD, et al. Adult tobacco use levels after intensive tobacco control measures: New York City, 2002-2003. Am J Public Health 2005:95:1016-23.

104. Siahpush M, Wakefield MA, Spittal MJ, et al. Taxation reduces social disparities in adult smoking prevalence. Am J Prev Med 2009;36:285-91.

105. Martire KA, Mattick RP, Doran CM, et al. Cigarette tax and public health: what are the implications of financially stressed smokers for the effects of price increases on smoking prevalence? Addiction 2011;106:622-30.

106. Verdonk-Kleinjan WM, Candel MJ, Knibbe RA, et al. Effects of a workplacesmoking ban in combination with tax increases on smoking in the Dutch population. Nicotine Tob Res 2011:13:412-18.

107. Glasgow RE, Vogt TM, Boles SM. Evaluating the public health impact of health promotion interventions: the RE-AIM framework. Am J Public Health 1999:89:1322-7.

108. National Center for Health Statistics, Centers for Disease Control and Prevention. About the National Health Interview Survey. 2011. http://www.cdc. gov/nchs/nhis/about nhis.htm (accessed 5 Dec 2011).

109. Gross CP, Soffer B, Bach PB, et al. State expenditures for tobacco-control programs and the tobacco settlement. N Engl J Med 2002;347:1080-6.

110. Fiore MC, Novotny TE, Pierce JP, et al. Methods used to quit smoking in the United States. JAMA 1990;263:2760-5.

111. Cokkinides VE, Ward E, Jemal A, et al. Under-use of smoking-cessation treatments-results from the national health interview survey, 2000. Am J Prev Med 2005;28:119-22.
112. Orleans CT, Mabry PL, Abrams DB. Increasing tobacco cessation in America: a consumer demand perspective. Am J Prev Med 2010;38:S303-6.

113. Kotz D, Fidler JA, West R. Did the introduction of varenicline in England substitute for or add to the use of other smoking cessation medications? Nicotine Tob Res 2011:13:793-9

114. Chapman S. The inverse impact law of smoking cessation. Lancet 2009;373:701-3

115. Walsh RA. Over-the-counter nicotine replacement therapy: a methodological review of the evidence supporting its effectiveness. Drug Alcohol Rev 2008:27:529-47.

116. Rothwell PM. External validity of randomised controlled trials: "to whom do the results of this trial apply?" Lancet 2005;365:82-93.

117. Shiffman S, Sweeney CT. Ten years after the Rx-to-OTC switch of nicotine replacement therapy: what have we learned about the benefits and risks of nonprescription availability? Health Policy 2008;86:17-26.

118. Shiffman S, Gorsline J, Gorodetzky CW. Efficacy of over-the-counter nicotine patch. Nicotine Tob Res 2002;4:477-83.

119. West R, Mcneill A, Britton J, et al. Should smokers be offered assistance with stopping? Addiction 2010;105:1867-9.

120. Warner KE, Burns DM. Hardening and the hard-core smoker: concepts, evidence, and implications. Nicotine Tob Res 2003;5:37-48.

121. Office on Smoking and Health, National Center for Chronic Disease Prevention and Health Promotion, Centers for Disease Control. Trends in Current Cigarette Smoking Among high School Students and Adults, United States, 1965-2010. 2011. http://www.cdc.gov/tobacco/data_statistics/tables/trends/ cig smoking/index.htm (accessed 5 Dec 2011).

122. Centers for Disease Control and Prevention. Cigarette smoking among adults and trends in smoking cessation-United States, 2008. MMWR 2009;58:1227-32.

123. Gilpin EA, Pierce JP. Demographic differences in patterns in the incidence of smoking cessation: United States 1950-1990. Ann Epidemiol 2002:12:141-50.

124. Lopez AD, Collishaw NE, Piha T. A descriptive model of the cigarette epidemic in developed countries. Tob Control 1994;3:242-7.

125. Wampold BE. The Great Psychotherapy Debate: Models, Methods, and Findings Mahwah, NJ: Lawrence Erlbaum Associates, Inc., 2001.

126. Zhu S, Gamst A, Anderson CM. A model of population cessation. 2011. Manuscript under editorial review.

127. Roeseler A, Anderson CM, Hansen K, et al, eds. Creating Positive Turbulence: $A$ Tobacco Quit Plan for California. Sacramento, CA: California Department of Public Health, California Tobacco Control Program, 2010. 